\title{
The effect of different dietary fats on gastrin levels in the pyloric antrum and plasma of weaner and adult Wistar rats
}

\author{
BY N. U. EKEKE, C. SHAW*, C. F. JOHNSTON, K. D. BUCHANAN \\ AND A. H. G. LOVE \\ Department of Medicine, The Queen's University of Belfast, Grosvenor Road, Belfast BT12 6BJ
}

(Received 3 July 1991-Accepted 7 January 1992)

\begin{abstract}
The effect of dietary fats on gastrin in the pyloric antrum and plasma of Wistar rats was examined. Two different age-groups of rats were fed on three different diets in which fat was in the form of menhaden oil (MO), hydrogenated coconut oil (CO) and safflower oil (SO) respectively. Control groups were fed on normal laboratory diet. Each diet was isoenergetic and no group showed significant differences in either food intake or weight gain during the experiment. Weaner rats fed on the MO diet exhibited significant reductions in both antral $(P=0.047)$ and plasma $(P=0.002)$ gastrin concentrations when compared with age-matched controls. Likewise, adult rats fed on the MO diet exhibited significant reductions in both antral $(P=0.008)$ and plasma $(P=0.002)$ gastrin concentrations. In addition, adult rats fed on the $\mathrm{CO}$ diet exhibited significant reductions in both antral $(P=0.047)$ and plasma gastrin $(P=0.002)$ concentrations. Rats from both age-groups fed on the SO diet exhibited no significant differences in gastrin concentrations when compared with their respective control groups. These findings indicate that the composition of dietary fat can have profound effects on both tissue and plasma concentrations of gastrin in rats.
\end{abstract}

Gastrin: Fat intake: Rat

Gastrin was discovered in 1905, when Edkin observed that extracts of the pyloric antrum stimulated gastric secretion when injected into the bloodstream of rats (Edkin, 1905). The full primary structure of this peptide hormone was not determined until 1964, when Gregory and his colleagues established that it was an acidic peptide of seventeen amino acid residues (Gregory et al. 1964). This structure was confirmed by successful chemical synthesis of bioactive peptide. In addition to its gastric secretory activity, gastrin is involved in the regulation of other gastrointestinal activities including growth, absorption and motility (Gingel et al. 1968; Crean et al. 1969; Lin \& Spray, 1969; Castell \& Harris, 1970). Gastrin occurs mainly in specialized secretory cells, the G-cells, within the epithelium of the pyloric glands (Greider et al. 1972) and gastrin release into the bloodstream is stimulated by a variety of factors. Luminal proteins and amino acids are the most powerful gastrin secretagogues, as is acetylcholine released from cholinergic terminals in close vicinity to the secretory cells (Korman et al. 1971; Lichtenberger \& Johnson, 1974; Lichtenberger et al. 1974, 1976; Strunz et al. 1977). In contrast, the presence of acid in the pylorus inhibits gastrin release possibly as a component of a feedback inhibitory mechanism (Gillespie \& Grossman, 1962).

The effect of dietary fat composition on plasma cholesterol levels, coronary heart disease and rheumatoid arthritis in man and laboratory animals is well documented (Dyerberg et al. 1978; Dremer et al. 1985; Channusot et al. 1988; Rand et al. 1988; Shinton et al. 1989). Cholecystokinin, a peptide sharing a common C-terminal active tetrapeptide amide with

\footnotetext{
* For reprints.
} 
Table 1. Composition $(\mathrm{g} / \mathrm{kg})$ of the three different experimental diets

\begin{tabular}{lrrr}
\hline \hline Diet... & MO & CO & SO \\
& & & \\
\hline Dietary component & $200 \cdot 0$ & $200 \cdot 0$ & $200 \cdot 0$ \\
Casein (high-nitrogen) & $3 \cdot 0$ & $3 \cdot 0$ & $3 \cdot 0$ \\
DL-methionine & $333 \cdot 8$ & $293 \cdot 8$ & $293 \cdot 8$ \\
Sucrose & $150 \cdot 0$ & $150 \cdot 0$ & $150 \cdot 0$ \\
Maize starch & $200 \cdot 0$ & - & - \\
Menhaden oil & - & $200 \cdot 0$ & - \\
Coconut oil (hydrogenated) & - & - & $200 \cdot 0$ \\
Safflower oil & $10 \cdot 0$ & - & - \\
Maize oil & $50 \cdot 0$ & $50 \cdot 0$ & $50 \cdot 0$ \\
Alphacel (bulk) & $1 \cdot 2$ & $1 \cdot 2$ & $1 \cdot 2$ \\
DL- $\alpha$-tocopherol (250 IU/g) & $40 \cdot 0$ & $40 \cdot 0$ & $40 \cdot 0$ \\
AIN-76 mineral mixture & $12 \cdot 0$ & $12 \cdot 0$ & $12 \cdot 0$ \\
ICN vitamin mix & - & - & - \\
\hline
\end{tabular}

MO, menhaden oil; CO, hydrogenated coconut oil; SO, safflower oil.

gastrin but localized predominantly to cells in the upper small intestine, is released into the circulation in response to luminal protein and fat. The effect of dietary fats on this release mechanism has been well documented (Meyer \& Jones, 1974; Renny et al. 1983) but the effect on gastrin secretion and gastrin levels in the pyloric antrum has not been previously reported. In the present study we have examined the effect of three different diets containing fat predominantly in the form of menhaden oil (MO), hydrogenated coconut oil (CO) and safflower oil (SO) respectively on the tissue levels and circulating concentrations of gastrin in two different age-groups of rats.

\section{MATERIALS AND METHODS \\ Experimental groups}

Both male and female Wistar rats were used. Five male and five female rats from each of the two age-groups were fed on either a diet rich in one of the three different oils or a standard laboratory rodent diet for 4 weeks. Animals were permitted free access to food and water for the duration of the experiment. Rats ( 3 weeks old; body weight range $38-57 \mathrm{~g}$ ) were weaned directly onto the different diets and adult rats (body weight range 225-380 g) were changed from a standard laboratory rodent diet onto the different diets. The compositions of the different diets are given in Tables $1-3$. Diets containing the three different oils were formulated by ICN Pharmaceuticals, High Wycombe, Bucks and standard laboratory rodent diet was purchased from Robert Morton and Company, Ballymena.

\section{Blood and tissue collection}

Rats were killed by intraperitoneal administration of a lethal dose ( $1 \mathrm{mg} / \mathrm{kg}$ body weight) of sodium pentobarbitone. Blood was withdrawn by cardiac puncture and placed into chilled heparinized tubes. Plasma was removed following centrifugation ( $1500 \mathrm{~g}$ for $20 \mathrm{~min}$ at $4^{\circ}$ ) and stored at $-20^{\circ}$ before gastrin radioimmunoassay (RIA). For RIA, the stomach was excised and opened along the greater curvature. Contents were removed by washing in ice-cold physiological saline solution ( $9 \mathrm{~g}$ sodium chloride/1) and the pyloric antrum was dissected out. For extraction of gastrin from frozen antral tissues, tissues were weighed while still frozen and then dropped into boiling sodium phosphate-buffered saline (PBS), 
Table 2. Composition $(\mathrm{g} / \mathrm{kg})$ of standard laboratory rodent diet

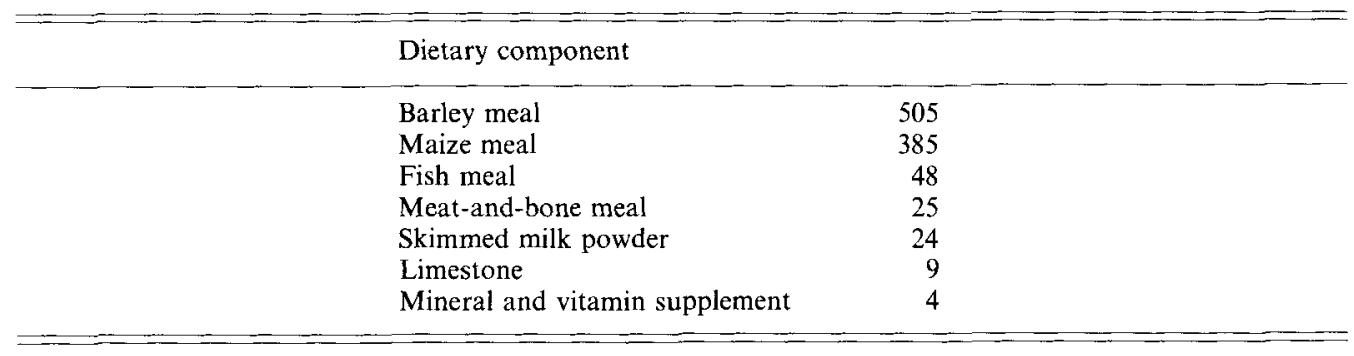

Table 3. Fatty acid compositions ( $\%$ total fat) of experimental and control diets*

\begin{tabular}{|c|c|c|c|c|}
\hline \multirow[b]{2}{*}{ Fatty acid } & \multicolumn{4}{|c|}{ Diet } \\
\hline & MO & $\mathrm{CO}$ & SO & Control \\
\hline $8: 0$ & - & $7 \cdot 36$ & - & 一 \\
\hline $10: 0$ & 一 & $5 \cdot 88$ & - & - \\
\hline $12: 0$ & $0 \cdot 20$ & $47 \cdot 87$ & 0.49 & $0 \cdot 16$ \\
\hline $14: 0$ & $11 \cdot 22$ & 19.94 & 0.37 & $1 \cdot 25$ \\
\hline $15: 0$ & 0.73 & - & - & 0.17 \\
\hline $15: 1$ cis & 0.11 & - & - & - \\
\hline $16: 0$ & 26.90 & $9 \cdot 40$ & $7 \cdot 76$ & $18 \cdot 55$ \\
\hline $16: 1$ trans & 0.41 & - & 一 & $-\ldots$ \\
\hline $16: 1$ cis & 14.54 & - & 0.12 & 1.04 \\
\hline $17: 0$ & 0.52 & - & - & 0.31 \\
\hline $17: 1$ cis & $1 \cdot 30$ & - & - & - \\
\hline $18: 0$ & 4.92 & $9 \cdot 54$ & 3.08 & 4.87 \\
\hline $18: 1$ trans & $1 \cdot 19$ & - & - & 0.49 \\
\hline $18: 1 \mathrm{cis}$ & 17.60 & - & 14.39 & $24 \cdot 77$ \\
\hline $18: 2$ trans & $0 \cdot 12$ & - & - & - \\
\hline $18: 2 \mathrm{cis}$ & 3.92 & - & 72.99 & $40 \cdot 14$ \\
\hline $18: 3 \mathrm{cis}$ & $2 \cdot 02$ & - & $0 \cdot 20$ & $2 \cdot 28$ \\
\hline $20: 0$ & 0.60 & - & $0 \cdot 39$ & $0 \cdot 31$ \\
\hline $20: 1 c i s$ & 0.28 & $-\cdots$ & $0 \cdot 21$ & $1 \cdot 20$ \\
\hline $20: 2 \mathrm{cis}$ & $0 \cdot 19$ & $一$ & - & - \\
\hline $20: 3 \mathrm{cis}$ & 0.90 & - & - & $0 \cdot 85$ \\
\hline 20 unknown & 0.97 & - & - & - \\
\hline $20: 5$ & 5.07 & - & - & $1 \cdot 14$ \\
\hline $22: 5 \mathrm{cis}$ & $1 \cdot 44$ & - & - & - \\
\hline $22: 6 c i s$ & $3 \cdot 68$ & - & - & $2 \cdot 48$ \\
\hline $24: 0$ & 0.68 & - & - & - \\
\hline $24: 1 \mathrm{cis}$ & $0 \cdot 48$ & - & - & - \\
\hline Saturated & $45 \cdot 80$ & $100 \cdot 00$ & $12 \cdot 10$ & $25 \cdot 60$ \\
\hline Monounsaturated & & & & \\
\hline (cis) & $34 \cdot 30$ & - & $14 \cdot 90$ & $27 \cdot 00$ \\
\hline Polyunsaturated & & & & \\
\hline (cis) & $18 \cdot 20$ & - & $73 \cdot 00$ & $46 \cdot 90$ \\
\hline (trans) & $1 \cdot 70$ & - & - & $0 \cdot 50$ \\
\hline Total fat $(\mathrm{g} / \mathrm{kg})$ & $199 \cdot 0$ & $187 \cdot 0$ & $195 \cdot 0$ & $38 \cdot 0$ \\
\hline
\end{tabular}

MO, menhaden oil; CO, hydrogenated coconut oil; SO, safflower oil.

* For details of composition, see Tables 1 and 2. 
Table 4. Concentrations of gastrin immunoreactivity in plasma and pyloric antral extracts from weaner rats fed on diets containing different fats (menhaden oil (MO), hydrogenated coconut oil $(\mathrm{CO})$ and safflower oil $(\mathrm{SO})$ )

(Values are means with their standard errors for five rats in each group)

\begin{tabular}{|c|c|c|c|c|}
\hline \multirow[b]{2}{*}{ Diet } & \multicolumn{2}{|c|}{ Plasma gastrin (ng/l) } & \multicolumn{2}{|c|}{ Antral gastrin $(\mathrm{ng} / \mathrm{g})$} \\
\hline & Mean & $\mathbf{S E}$ & Mean & $\mathrm{SE}$ \\
\hline Standard laboratory rodent & 215 & 62 & 977 & 140 \\
\hline MO & $48^{*}$ & 7 & $677^{* *}$ & 105 \\
\hline $\mathrm{CO}$ & 113 & 27 & 756 & 80 \\
\hline $\mathrm{SO}$ & 173 & 51 & 1240 & 268 \\
\hline
\end{tabular}

$\mathrm{pH} 7 \cdot 2$, for a period of $15 \mathrm{~min}$. The resulting aqueous extract was centrifuged to remove tissue debris and the supernatant fraction was stored at $-20^{\circ}$ before gastrin RIA.

\section{$R I A$}

Plasma and tissue extracts were subjected to gastrin RIA using antiserum R98 which was raised to synthetic human gastrin 2-17 and which cross-reacts fully with rat gastrin 17 but not with cholecystokinin (Ardill, 1979). All samples were assayed in duplicate serial dilution. Using a gastrin tracer purified by reverse-phase high-performance liquid chromatography, this assay could detect $0.1 \mathrm{pg}$ gastrin 17 /assay tube with $95 \%$ confidence.

\section{Statistical analyses}

The means with their standard errors for both plasma and antral gastrin concentrations were calculated for each age-group on each diet. For group comparisons the unpaired Student's $t$ test followed by the Mann-Whitney $U$ test was applied. Significance values of $P<0.05$ were considered significant.

\section{RESULTS}

Consumption of food and weight gain

Each of the different diets appeared to be equally palatable to the rats as indicated by the daily consumption. Body weight gain in weaner rats (range 120-180 g) was greater than that observed in the adult rats (range 18-29 g), as was expected. However, weight gain in rats fed on the different diets was not significantly different within each age-group.

\section{$R I A$}

Weaner rats. The concentrations of gastrin in pyloric antral extracts and in plasma of weaner rats on the different dietary fat regimens are summarized in Table 4 . As no significant differences were found between sexes in each experimental group, the values from both male and female rats were pooled throughout. When compared with weaner rats fed on standard laboratory rodent diet, the group fed on the MO diet had significantly lower $(P=0.002)$ levels of plasma gastrin. This effect was mirrored in the concentration of gastrin in pyloric antral extracts of both groups with significantly lower levels $(P=0.047)$ in the antral tissues from rats fed on the MO diet. There were no significant differences in either plasma gastrin or antral gastrin concentrations in the groups fed on CO or SO diets when compared with controls. 
Table 5. Concentrations of gastrin immunoreactivity in plasma and pyloric antral extracts from adult rats fed on diets containing different dietary fats (menhaden oil (MO), hydrogenated coconut oil ( $\mathrm{CO})$ and safflower oil $(\mathrm{SO})$ )

(Values are means with their standard errors for five rats in each group)

\begin{tabular}{lccccc}
\hline & \multicolumn{2}{c}{ Plasma gastrin $(\mathrm{ng} / \mathrm{l})$} & & \multicolumn{2}{c}{ Antral gastrin $(\mathrm{ng} / \mathrm{g})$} \\
\cline { 3 - 6 } Diet & Mean & SE & & Mean & SE \\
\hline Standard laboratory rodent & 162 & 5 & & 1025 & 163 \\
MO & $90^{*}$ & 8 & & $452^{* *}$ & 38 \\
CO & $107^{*}$ & 11 & & $571^{* * *}$ & 54 \\
SO & 132 & 11 & & 709 & 71 \\
\hline
\end{tabular}

$$
{ }^{*} P=0.002,{ }^{* *} P=0.008, * * * P=0.047 \text {. }
$$

Adult rats. The concentrations of gastrin in pyloric antral extracts and plasma of adult rats on the different dietary fat regimens are summarized in Table 5. As no significant differences were found between sexes in each experimental group, the values from both males and females were pooled. Adult rats fed on the MO diet exhibited similar significant reductions in both antral and plasma gastrin concentrations as observed in weaner rats ( $P=0.008$ and 0.002 respectively), when compared with appropriate adult controls. In addition to this, adult rats fed on the $\mathrm{CO}$ diet, exhibited significant reductions in both antral $(P=0.047)$ and plasma $(P=0.002)$ gastrin concentrations when compared with appropriate adult controls. The SO diet had no significant effect on either tissue or circulating levels of gastrin in adult rats.

\section{DISCUSSION}

The present study was performed to assess the effect of high-fat diets and type of dietary fat on tissue and circulating levels of the pyloric antral hormone gastrin in rats. Two different age-groups of rats were employed. Groups of young rats, approximately 3 weeks old, were weaned directly onto the three experimental diets and a control group was weaned onto a standard laboratory rodent diet. The second age-group studied consisted of adult rats, approximately 12 weeks old, which had been weaned 9 weeks previously onto a standard laboratory rodent diet. While a control group was maintained on this diet for the duration of the experiment, a further three groups were fed on the experimental diets. The two age-groups of rats were employed to assess the effects of possible dietary acclimation on the experimental results. All the diets were formulated isoenergetically and all were apparently equally palatable as judged by the similar daily intake of each recorded. The weight gains within each age-group were not significantly different on the different diets although, as would be expected, the younger rats gained more weight than the adults during the time-course of the experiment.

The diet containing MO had a pronounced effect in significantly reducing both antral and plasma gastrin concentrations in both age-groups of rats. This diet contained a broad spectrum of different chain-length fatty acids and these were distributed between monounsaturated, polyunsaturated and saturated types, with a high relative concentration of monounsaturates. In addition, oils derived from certain species of fish such as the menhaden, are known to be rich in $n-3$ fatty acids which have well-documented cytoprotective effects. This diet, thus, provides a balanced intake of lipids of different types and, interestingly, is the only one containing lipid predominantly of animal origin. In 
contrast, $\mathrm{CO}$ and $\mathrm{SO}$, both of vegetable origin, consist largely of fatty acids of a limited range of chain-lengths which are either predominantly saturated or polyunsaturated respectively. However, it cannot be stated unequivocally from the present data that the fatty acids contained within each different oil are responsible for the changes observed in antral and plasma gastrin concentrations, as additional unidentified components in each may possess secretory modulatory activity. It has been reported previously that the gastric secretory response in rats fed on synthetic, chemically-defined diets was reduced when compared with rats fed on standard laboratory rodent diet (Sicar et al. 1980). It was deduced from this finding that synthetic diets lack some undefined food constituents required for the normal post-prandial release of gastrin or, alternatively, contained an inhibitory factor which attenuated the normal secretory response. Although these observations may have been relevant to the studies cited, it is more difficult to ascribe them as contributory factors to the present findings as, in both adult and weaner rats, the effects of the experimental diets on gastrin concentrations were variable. In addition, each experimental diet contained considerably higher proportions of fat $(180-200 \mathrm{~g} / \mathrm{kg})$ than the standard laboratory rodent diet $(38 \mathrm{~g} / \mathrm{kg})$. The parallel reduction in both tissue and circulating levels of gastrin, observed most dramatically in those rats fed on the MO diet, would tend to suggest that both inhibition of synthesis and release of this peptide hormone had been induced. Dietary protein has previously been regarded as the most potent macronutrient in stimulating release of gastrin from the pyloric antrum (Dockray, 1978). The mechanism of response is thought to involve an elevation in intragastric $\mathrm{pH}$, due to the inherent buffering capacity of proteins, which is detected by chemosensitive microvilli on the apical lumen surfaces of gastrin-producing pyloric endocrine cells which, in turn, respond by secretion of gastrin which stimulates parietal cell acid secretion and chief cell pepsinogen secretion (Black et al. 1972). It is highly unlikely that the effects on antral gastrin observed in the present study are protein-related as each experimental diet contained the same protein source (casein) in identical quantities.

Although the present study has employed rats as an experimental model and extrapolation of findings in this species to the human is fraught with danger, the ability to reduce both tissue and circulating gastrin concentrations by simple dietary manipulation is an area which may warrant further study in humans for several important reasons. As gastrin is a major gastric acid secretagogue, reduction in its stimulation potential by simple dietary manipulation may prove to be a useful tool in the clinical management of patients with duodenal ulceration. Current treatment regimens include the use of drugs which are histamine-receptor antagonists or which inhibit the proton pump on the parietal cell membrane (Black et al. 1972; Bank et al. 1976). Whilst both are effective they have limitations in their usage due to either rebound phenomena when the drug is withdrawn or total inhibition of acid secretion, respectively. Gastrin has also been shown to possess trophic effects on the colonic mucosa (Crean et al. 1969). This biological effect may, in hypersecretory states, lead to a predisposition to colonic neoplasia. This latter situation in itself is known to involve a dietary component, especially with respect to saturated fat of animal origin.

In conclusion, a diet rich in MO causes significant reductions in both circulating and tissue concentrations of the endogenous gastric acid secretagogue, gastrin in rats, irrespective of age or previous dietary acclimation. These observations may be of relevance in human dietary strategies, especially in individuals with peptic ulcer disease.

This work was funded by a PhD studentship from the Nutritional Consultative Panel of the UK Dairy Industry to N.U.E. The authors are indebted to Dr J. Stevens, St Ivel Ltd, Swindon, for performing fatty acid analyses. 


\section{REFERENCES}

Ardill, J. E. S. (1979). Radioimmunoassay of gastrointestinal hormones, Clinics in Endocrinology and Metabolism 8, 265-280.

Bank, S., Barbezat, G. O., Novis, B. H., Ou, T., Odes, H. S., Helman, C., Narunsky, L., Duys, P. J. \& Marks, I. N. (1976). Histamine $-\mathrm{H}_{2}$ receptor antagonists in the treatment of duodenal ulcers. South African Medical Journal 50, 1781-1784.

Black, J. W., Duncan, W. A. M., Durant, G. J., Ganellin, C. R. \& Parson, E. M. (1972). Definitions and antagonism of histamine- $\mathrm{H}_{2}$ receptors. Nature 236, 385-390.

Castell, D. O. \& Harris, L. D. (1970). Hormonal control of gastroesophageal sphincter strength. New England Journal of Medicine 282, 886-890.

Channusot, F., Esnault-Dupuy, C., Matigne, M., Portugal, H., Lairon, D., Quingard, A., Alcindor, G. L., Pauli, A. M., Lafont, H. \& Hauton, C. J. (1988). Metabolism of low- and high-density lipoprotein-free-cholesterol in rats fed high fat diets. Annals of Nutrition \& Metabolism 32, 271-281.

Crean, G. P., Marshall, M. W. \& Rumsey, R. D. G. (1969). Parietal cell hyperplasia induced by the administration of pentagastrin to rats. Gastroenterology 57, 147-155.

Dockray, G. J. (1978). Gastrin overview. In Gut Hormones, pp. 129-139. [S. R. Bloom, editor]. Edinburgh, London and New York: Churchill Livingstone.

Dremer, J. M., Michalek, A. V., Lininger, L., Huych, C., Bigauoette, J., Timchalk, M. A., Rynes, R. I., Rieminski, J. \& Bartholomew, L. E. (1985). Effects of manipulation of dietary fatty acid on clinical manifestations of rheumatoid arthritis. Lancet $\mathbf{i}, 184-187$.

Dyerberg, T., Bank, H. O., Stofferson, E., Moncada, S. \& Vane, J. R. (1978). Eicosapentaenoic acid and prevention of thrombosis and atherosclerosis. Lancet ii, 117-119.

Edkin, J. S. (1905). On the chemical mechanism of gastric secretion. Proceedings of the Royal Society of Biology 76, 376.

Gillespie, I. E. \& Grossman, M. I. (1962). Effect of acid in pyloric pouch on response of fundic pouch to injected gastrin. American Journal of Physiology 203, 557-562.

Gingel, J. C., Davies, M. W. \& Shields, R. (1968). Effect of a synthetic gastrin-like pentapeptide upon the intestinal transport of sodium, potassium and water. Gut 5, 1911-1916.

Gregory, R. A., Davies, M. W. \& Tracy, H. J. (1964). The constitution and properties of the two gastrins extracted from hog antral mucosa. Gut 5, 103-117.

Greider, M. H., Steinberg, V. \& McGuigan, J. E. (1972). Electron microscope identification of the gastrin cell of the human antral mucosa by means of immunocytochemistry. Gastroenterology 63, 572-582.

Korman, M. G., Sorveny, C. \& Hanky, J. (1971). Effect of food on serum gastrin evaluated by radioimmunoassay. Gut 12, 619-624.

Lichtenberger, L. M., Castro, G. A., Copeland, E. M., Dudrick, S. J. \& Johnson, L. R. (1974). The effect of food on rat antral gastrin concentration. Gastroenterology 55, 220.

Lichtenberger, L. M. \& Johnson, L. R. (1974). Gastrin in the ontogenic development of the small intestine. American Journal of Physiology 227, 390-395.

Lichtenberger, L. M., Welsh, J. D. \& Johnson, L. R. (1976). Relationship between the exchanges in gastrin levels and intestinal properties in the starved rat. American Journal of Digestive Diseases 21, 33.

Lin, T. M. \& Spray, G. F. (1969). Effect of pentagastrin, cholecystokinin, caerulein and glucagon on the choledochal resistance and bile flow of the conscious dog. Gastroenterology 56, 1178.

Meyer, J. \& Jones, R. (1974). Canine pancreatic responses to intestinally perfused fat and products of fat digestion. American Journal of Physiology 226, 1178-1187.

Rand, L. M., Hennissen, A. H. M. \& Hornstra, G. (1988). Effects of dietary palm oil on arterial thrombosis, platelet responses and platelet membrane fluidity in rats. Lipids 23, 1019-1023.

Renny, A., Snape, W., Sun, E., London, R. \& Cohen, S. (1983). Role of cholecystokinin in the gastrocolonic response to a fat meal. Gastroenterology $85,17-21$.

Shinton, R. A., Dodson, P. M. \& Beevers, D. G. (1989). Hypertension and dietary fat. Journal of Human Hypertension 3, 73-78.

Sicar, B., Johnson, L. R. \& Lichtenberger, L. M. (1980). Effect of chemically defined diets on antral and serum gastrin levels in rats. American Journal of Physiology 238, G376-G383.

Strunz, U. T., Walsh, J. H. \& Grossman, M. I. (1977). Stimulation of gastrin release and gastric acid secretion by various amino acids. Clinical Research 24, 113. 